\title{
Monitoring ovarian function and pregnancy in Eld's deer (Cervus eldi thamin) by evaluating urinary steroid metabolite excretion
}

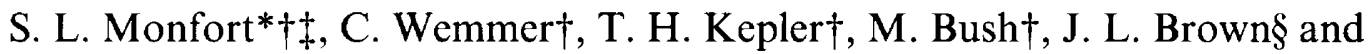 \\ D. E. Wildt $\dagger \ddagger$ \\ $\dagger$ National Zoological Park, Smithsonian Institution, Washington, D.C. 20008, USA; \\ $\ddagger$ Department of Biology, George Mason University, Fairfax, Virginia 22030, USA; and \\ $\$$ Department of Obstetrics and Gynecology, Uniformed Services University for the Health Sciences, \\ Bethesda, Maryland 20814, USA
}

\begin{abstract}
Summary. Direct radioimmunoassays (RIA) for urinary oestrone conjugates and pregnanediol-3 $\alpha$-glucuronide $(\mathrm{PdG})$ were used to study ovarian activity patterns and pregnancy in Eld's deer. In 2 does, urinary metabolite patterns were compared to temporal patterns of plasma $\mathrm{LH}$, oestradiol-17 $\beta$ and progesterone. Preovulatory $\mathrm{LH}$ peaks occurred coincident with behavioural oestrus, and plasma progesterone secretion paralleled PdG excretion. Although plasma oestradiol-17 $\beta$ levels fluctuated between 5 and $10 \mathrm{pg} / \mathrm{ml}$ throughout the oestrous cycle, no preovulatory oestrogen surge was observed. Based on PdG excretion, non-conception oestrous cycles averaged $21 \cdot 5 \pm$ $2 \cdot 1$ days ( \pm s.e.m., $n=65$ ); however, 2 of 13 does exhibited prolonged oestrous cycles (30.1 $\pm 4 \cdot 4$ days; range 14-62 days, $n=14$ ) characterized by sustained PdG excretion. Excluding these 2 females, the mean oestrous cycle was $18.5 \pm 0.3$ days (range 14-23 days, $n=51$ ). Behavioural oestrus (12-24 h duration) was observed in 42 of 65 cycles (64.6\%), and always corresponded with intercyclic troughs in PdG excretion (2-5 days duration). Mean gestation duration $(n=10)$ was $33.5 \pm 0.4$ weeks. PdG concentrations increased $(P<0.05)$ by Week -32 (3rd week of gestation), plateaued between Weeks -31 and -25 , increased $(P<0.05)$ markedly by Week -22 and then rose steadily until parturition, declining $(P<0.05)$ rapidly thereafter. Mean excretion of oestrone conjugates remained low until Week -30 , increased $(P<0.05)$ steadily to Week -24 $(P<0.05)$ and then returned to baseline by Week -17 . Increased $(P<0.05)$ oestrone conjugates concentrations were detected again by Week -4 followed by a rapid increase to peak pregnancy levels by Week -1 , declining $(P<0.05)$ precipitously after parturition. The results confirm that the Eld's deer is seasonally polyoestrous with onset (January-March) and cessation (August-October) of regular, cyclic ovarian activity coinciding with increasing and decreasing daylengths, respectively. Urinary $\mathrm{PdG}$ excretion accurately reflects cyclic ovarian activity and markedly elevated concentrations of this metabolite provide an accurate index of pregnancy. The simultaneous monitoring of oestrone conjugates appears useful for estimating the stage of pregnancy and predicting parturition onset.
\end{abstract}

Keywords: Eld's deer; oestrogen; progesterone; urinary steroids; LH; seasonality

*Address for correspondence: Dr S. L. Monfort, National Zoological Park, Conservation and Research Center, Route 522 South, Front Royal, Virginia 22630, USA. 


\title{
Introduction
}

Although once ranging from Manipur in eastern India to Indochina and southern China (between $3^{\circ}$ and $25^{\circ} \mathrm{N}$ latitude), the Eld's deer (Cervus eldi) is endangered and exists primarily in small herds maintained in captivity (Wemmer \& Grodinsky, 1988). Behavioural studies suggest that does are seasonally polyoestrous and have an oestrous cycle of $\sim 17$ days in length. Oestrous behaviour generally is observed in late winter or early spring, and gestation lasts $\sim 35$ weeks with $80 \%$ of births occurring between September and November (Wemmer \& Grodinsky, 1988). Although basic captive management protocols have been established for the Eld's deer, reproductive endocrinology of the species has not been studied.

Hormonal analysis of serial blood samples has been used to study reproductive patterns in red deer (Guinness et al., 1971; Kelly et al., 1982), roe deer (Sempere, 1977; Hoffman et al., 1978; Schams et al., 1980), white-tailed deer (Plotka et al., 1977a, b, 1980), fallow deer (Asher, 1985; Asher et al., 1986), Père David's deer (Curlewis et al., 1988), reindeer and caribou (McEwan \& Whitehead, 1979). Because of their nervous behaviour and susceptibility to the manipulatory stresses associated with capture and restraint, cervid species are difficult to study. In white-tailed deer (Plotka et al., 1983) and fallow deer (Asher et al., 1989) does, a substantial proportion of serum progesterone is secreted from the adrenal glands. This suggests that long-term, sequential blood sampling, which often is impractical for monitoring reproductive patterns in wildlife species, can result in data confounded by the stresses associated with animal handling.

Excretory patterns of urinary oestrone conjugates and/or pregnanediol-3a-glucuronide (PdG), determined by direct radioimmunoassay (RIA), have been found to reflect reproductive activity accurately in the scimitar-horned oryx, bongo, okapi, giraffe (Loskutoff et al., 1982, 1983, 1986), Indian rhinoceros (Kasman et al., 1986), black rhinoceros (Ramsay et al., 1987), tapir (Kasman et al., 1985) and domestic horse (Evans et al., 1984; Kirkpatrick et al., 1988). This approach eliminates the stress associated with frequent venepuncture and permits daily, long-term tracking of endocrine activity. The present study applied these techniques to documenting the circannual reproductive patterns of the female Eld's deer, a tropical, 'long-day' breeding species. A longitudinal protocol was developed to identify seasonal reproductive activity, define the length of the oestrous cycle and diagnose pregnancy and parturition onset.

\section{Materials and Methods}

\begin{abstract}
Animals and sample collection. Thirteen hand-reared, female Eld's deer (2-8 years of age; $50-90 \mathrm{~kg}$ body weight) were housed at the National Zoological Park's Conservation and Research Center, Front Royal, VA ( $38^{\circ} \mathrm{N}$ latitude). Does were maintained individually in stalls $(3.4 \times 4.6 \mathrm{~m})$ connected to outdoor enclosures $(3.6 \times 36.6 \mathrm{~m})$ and were exposed to normal fluctuations in photoperiod. All females were in visual and olfactory proximity to each other and one or more intact males. Diet consisted of alfalfa hay and herbivore chow (15.5\% crude protein, $3.0 \%$ crude fat, $16.0 \%$ crude fibre; Ralston Purina Co., St Louis, MO, USA) and free access to a mineral block and water. Does were observed twice daily (early morning, late afternoon) for behavioural signs of oestrus which included scent marking of technicians with preorbital gland secretions and assuming a humped-back, lordotic stance when pressure was applied to the hindquarters.

Urine samples $(1-5 \mathrm{ml})$ were collected daily $(07: 00-11: 00 \mathrm{~h})$ by midstream catch or by aspirating urine pooled on enclosure floors. Eight non-pregnant females were sampled for periods ranging from 36 to 64 weeks. Ten females were monitored at different intervals during pregnancy ranging from 4 to 37 weeks before parturition through 7 weeks post partum. Samples were frozen immediately after collection $\left(-20^{\circ} \mathrm{C}\right)$, stored for $1-7$ days, thawed, centrifuged briefly $(1500 \mathrm{~g}, 10 \mathrm{~min})$ to remove particulate matter and then assayed.

For validation purposes, urinary hormone excretion patterns were compared with temporal hormone profiles in the peripheral circulation. Serial blood samples $(8 \mathrm{ml})$ were collected by jugular venepuncture from 2 females sedated with xylazine (Rompun ${ }^{\circledR}$ : Haver, Shawnee, KA, USA; $5-10 \mathrm{mg} /$ female, administered i.m.). Sampling was initiated in August, and proceeded at $48 \mathrm{~h}$ intervals until 2 behavioural oestrous periods were observed for each doe. Plasma was collected after centrifugation and immediately stored frozen $\left(-70^{\circ} \mathrm{C}\right)$ until assayed.
\end{abstract}

Creatinine assay. To compensate for variations in urine concentration, urinary creatinine $(\mathrm{Cr})$ was determined using a modified Jaffe reaction (Taussky, 1954). Diluted urine samples $(100 \mu 1,1: 100)$ were combined in duplicate (in 96-well microplates) with $50 \mu \mathrm{l}$ each picric acid $(0.40 \mathrm{M})$ and $\mathrm{NaOH}(0.75 \mathrm{M})$. After a $20 \mathrm{~min}$ incubation, absorbance 
(490 mm) was measured on an MR600 microplate reader (Dynatech, Chantilly, VA, USA). Hormone levels were divided by creatinine concentrations and values expressed as mass units $/ \mathrm{mg}$ Cr. Urinary creatinine concentrations averaged $1.37 \pm 0.05 \mathrm{mg} \mathrm{Cr} / \mathrm{ml}$ urine $(n=3362$ samples $)$ and inter- and intra-assay coefficients were $10 \cdot 3 \%(n=20)$ and $\leqslant 5 \%$, respectively.

Oestrone conjugates assay. Urinary oestrone conjugates were analysed with minor modifications of the RIA described by Shideler et al. (1983). Identification of specific oestrogen metabolites for Eld's deer was not performed by chromatographic separation, so only oestrone conjugates immunoreactivity was assessed. Initially, urine samples were diluted (1:50) in phosphate-buffered saline (PBS; 0.1 $\mathrm{M}, 0.1 \%$ gelatin, pH 7.0), and an aliquant (non-pregnant and early pregnant, $150 \mu \mathrm{l}$; late pregnant, $20 \mu \mathrm{l}$ ) was adjusted to a final assay volume of $300 \mu \mathrm{l}$ in Tris buffer (0.1 $\mathrm{M}$-Tris, $0.9 \% \mathrm{NaCl}, 0 \cdot 1 \% \mathrm{NaN}_{3}, 0 \cdot 1 \%$ gelatin, $\left.\mathrm{pH} 8 \cdot 4\right)$. The antiserum which cross-reacts $100 \%$ with oestrone glucuronide and oestrone sulphate (anti-oestrone-3-glucuronide serum, $100 \mu \mathrm{l}, 1: 1500$ : D. Collins, Emory University, Atlanta, GA, USA) and $\left[{ }^{3} \mathrm{H}\right]$ oestrone sulphate $(100 \mu \mathrm{l}, 7000$ c.p.m., sp. act. $55 \mathrm{Ci} / \mathrm{mmol}$ : Dupont-New England Nuclear, Wilmington, DE, USA) were combined with unknowns and standards (4.9-2500 pg/tube, Sigma Chemical Co., St Louis, MO, USA) and incubated overnight at $4 \%$ C. Following the addition of $300 \mu \mathrm{l}$ charcoal-dextran $(0 \cdot 0625 \%$ Norit $\mathrm{A}$ charcoal, $0 \cdot 00625 \%$ dextran in $0.1 \mathrm{M}$-PBS, $\mathrm{pH} \mathrm{7.0})$ and a $30-\mathrm{min}$ incubation at $4^{\circ} \mathrm{C}$, tubes were centrifuged $(10 \mathrm{~min}, 1500 \mathrm{~g})$, decanted into scintillation vials, combined with $5.0 \mathrm{ml}$ Ready Solv HPb (Beckman Instruments Inc., Fullerton, CA, USA) and counted for $5 \mathrm{~min}$.

Serial dilutions of Eld's deer urine yieided displacement curves parallel to that obtained for oestrone sulphate standards. The mean \pm s.e.m. recovery of oestrone sulphate (range; 4.9-2500 pg/tube) added to a pool of Eld's deer urine (1:50) was $92.4 \pm 3.9 \%(y=0.98 x-32.97 ; r=0.99 ; P<0.001)$. Assay sensitivity was $4.9 \mathrm{pg} /$ tube, interassay coefficients of variation for 2 separate internal controls were both $11.6 \%(n=38)$ and intra-assay variation averaged $\leqslant 10 \%$.

Pregnanediol-3a-glucuronide assay. Urinary PdG immunoreactivity was analysed using the methods of Mitchell $e t$ al. (1982) and Loskutoff et al. (1982). A sample of urine diluted (1:50) in PBS (non-pregnant, $100 \mu 1 ;$ pregnant, $25 \mu 1$ ) was combined with $100 \mu \mathrm{l} \mathrm{PdG}$ antiserum which cross-reacts $100 \%$ with PdG and $6.7 \%$ with pregnanediol $(\sharp 02 / Z$ Zoo, 1:20000) and $100 \mu \mathrm{l}\left[{ }^{3} \mathrm{H}\right] \mathrm{PdG}(7000$ c.p.m., sp. act. $42 \mathrm{Ci} / \mathrm{mmol})$ supplied by Courtauld Institute of Biochemistry, London, UK. Urines and standards (19.5-5000 pg/tube, Sigma Chemical Co.) were incubated overnight (4 $\left.{ }^{\circ} \mathrm{C}\right)$ and antibody-bound and free steroid were separated after a $45-\mathrm{min}$ incubation with $300 \mu$ charcoal-dextran suspension and centrifugation for $10 \mathrm{~min}(1500 \mathrm{~g})$. Supernatants were combined with $5 \mathrm{ml}$ Ready Solv HPb and counted for $5 \mathrm{~min}$.

Serial dilutions of Eld's deer urine yielded displacement curves parallel to that obtained with standard preparations. Recovery of known amounts of PdG (range; $19 \cdot 5-5000 \mathrm{pg} /$ tube) added to a pool of diluted urine (100 $\mu \mathrm{l}, 1: 50)$ gave a mean \pm s.e.m. value of $95.3 \pm 2.5 \%(y=0.97 x-12.66 ; r=1.0 ; P<0.001)$. Assay sensitivity was $19.5 \mathrm{pg} /$ tube and inter-assay coefficients of variation were $7.4 \%(n=55)$ and $12.6 \%(n=57)$ for 2 separate internal controls, and intraassay variation was $\leqslant 10 \%$.

Luteinizing hormone assay. Plasma LH was analysed using the procedure of Niswender et al. (1969). Serial dilutions of Eld's deer plasma yielded displacement curves parallel to that obtained with NIH-LH-S1 8 standards. The mean \pm s.e.m. recovery of $\mathrm{LH}$ (range, $0.03-4 \mathrm{ng} /$ tube) added to $100 \mu$ l pooled Eld's deer plasma was $98 \cdot 2 \pm 3 \cdot 1 \%(y=0 \cdot 98 x-1 \cdot 51$; $r=0.99 ; P<0.001)$. Assay sensitivity was $0.03 \mathrm{ng} /$ tube. The inter-and intra-assay coefficients of variation were $8.5 \%$ $(n=6)$ and $\leqslant 10 \%$, respectively.

Oestradiol-17\% and progesterone assays. Plasma oestradiol-17 $\beta$ and progesterone were analysed in unextracted plasma using commercially available RIA kits (Radiosystems Laboratories, Carson, CA, USA). For the oestradiol$17 \beta$ assay, the antiserum was anti-6-keto-oestradiol-17 $\beta$-6-oxime-BSA which cross-reacts $100 \%$ with oestradiol-17 $\beta$, $20 \%$ with oestrone and $1.5 \%$ with oestriol. Serial dilutions of unextracted Eld's deer serum (spiked with 1000 pg oestradiol- $17 \beta / \mathrm{ml}$ ) yielded displacement curves parallel to that obtained for oestradiol-17 $\beta$ standards prepared in Eld's deer plasma. The mean \pm s.e.m. recovery of oestradiol- $17 \beta$ (range $5-3000 \mathrm{pg} / \mathrm{ml}$ ) added to $100 \mu 1$ pooled Eld's deer plasma was $92.7 \pm 3.6 \%(y=1.03 x-10.51, r=0.99, P<0.001)$. Assay sensitivity was $5 \mathrm{pg} / \mathrm{ml}$; all samples with undetectable oestradiol- $17 \beta$ values were assigned a value of $5 \mathrm{pg} / \mathrm{ml}$ for analysis and presentation. The inter- and intra-assay coefficients were $8.5 \%(n=6)$ and $\leqslant 10 \%$, respectively.

For the progesterone analysis, antiserum was anti- $11 \alpha$-hydroxyprogesterone- 11 -hemisuccinate-HSA which crossreacts $100 \%$ with progesterone, $5.4 \%$ with $20 \alpha$-dihydroprogesterone and $3.8 \%$ with desoxycorticosterone. Serial dilutions of unextracted Eld's deer plasma yielded displacement curves parallel to that obtained for progesterone standards prepared in Eld's deer plasma. The mean \pm s.e.m. recovery of progesterone (range, $0 \cdot 2-50 \mathrm{ng} / \mathrm{ml}$ ) added to $100 \mu \mathrm{l}$ pooled Eld's deer plasma was $93.3 \pm 3 \cdot 1 \%(y=0.9 x-1.31, r=0.99, P<0.001)$. Assay sensitivity was $0 \cdot 2 \mathrm{ng} /$ tube. The inter- and intra-assay coefficients of variation were $7 \cdot 5 \%(n=6)$ and $\leqslant 10 \%$, respectively.

Definitions and statistical analyses. Oestrous cycle length was determined by measuring the interval between successive intercyclic nadirs in PdG excretion, and Day 1 of the cycle was defined as the first day PdG excretion returned to baseline concentrations ( $<10 \mathrm{ng} / \mathrm{mg} \mathrm{Cr}$ ). Gestation duration was considered as the interval from observed copulation until the birth of an offspring. Statistics were performed using Statview $512^{+\mathrm{TM}}$ (Version 1.1, BrainPower, Inc. 1986, Calabasas, CA, USA) on an Apple ${ }^{\circledR}$ Macintosh Plus Computer (Cupertino, CA, USA). Standard descriptive statistics including mean and standard error of the mean (s.e.m.) were used to describe hormonal metabolite values. Linear regression analyses were used to evaluate the correspondence between serum progesterone and urinary PdG. Urine 
values were used to predict serum values collected on the same day and 1 day apart to account for a potential lag in urinary metabolite excretion. Because serum samples were not collected every day, paired values vary from 11 to 16 points per individual. Differences among mean weekly hormone concentrations were determined by 1-way analysis of variance, and multiple pairwise comparisons between weeks were analysed using Fisher's Protected Least Significant Difference Test (Fisher, 1966).

\section{Results}

Urinary PdG values coincided with circulating progesterone collected on the same day in the 2 does subjected to urine and blood collection (Doe 1: $r=0.736, P<0.01$; Doe 2: $r=0.805, P<0.001$ ). Urinary PdG was a better predictor of serum progesterone when the former values lagged by $24 \mathrm{~h}$ (Doe 1: $r=0.828, P<0.002$; Doe 2: $r=0.895, P<0.001$ ). As demonstrated below, concentrations of oestrone conjugates in urine were ineffective for monitoring reproductive cyclicity of Eld's deer. Plasma progesterone, urinary PdG and plasma oestradiol-17 $\beta$ and LH profiles from one female are presented in Fig. 1. Behavioural oestrus occurred when plasma progesterone concentrations were at nadir $(\sim 0.25 \mathrm{ng} / \mathrm{ml})$. Following presumed ovulation, plasma progesterone eventually peaked at $1.8 \mathrm{ng} / \mathrm{ml}$. The urinary $\mathrm{PdG}$ excretory profile was similar qualitatively to plasma progesterone; $\mathrm{PdG}$ concentrations increased to $\sim 70 \mathrm{ng} / \mathrm{mg} \mathrm{Cr}$ during the luteal phase, decreased to $<10 \mathrm{ng} / \mathrm{mg} \mathrm{Cr}$ during the follicular phase with basal levels also occurring coincident with oestrus. Plasma LH concentrations remained below $0.25 \mathrm{ng} / \mathrm{ml}$ during the follicular and luteal phase but increased approximately 6-fold during a presumed preovulatory peak $(1.5 \mathrm{ng} / \mathrm{ml})$ coinciding with behavioural oestrus. Plasma oestradiol-17 $\beta$ concentrations in both does fluctuated between 5 and $10 \mathrm{pg} / \mathrm{ml}$ during the sampling interval with no evidence of a pre-LH surge (Fig. 1).
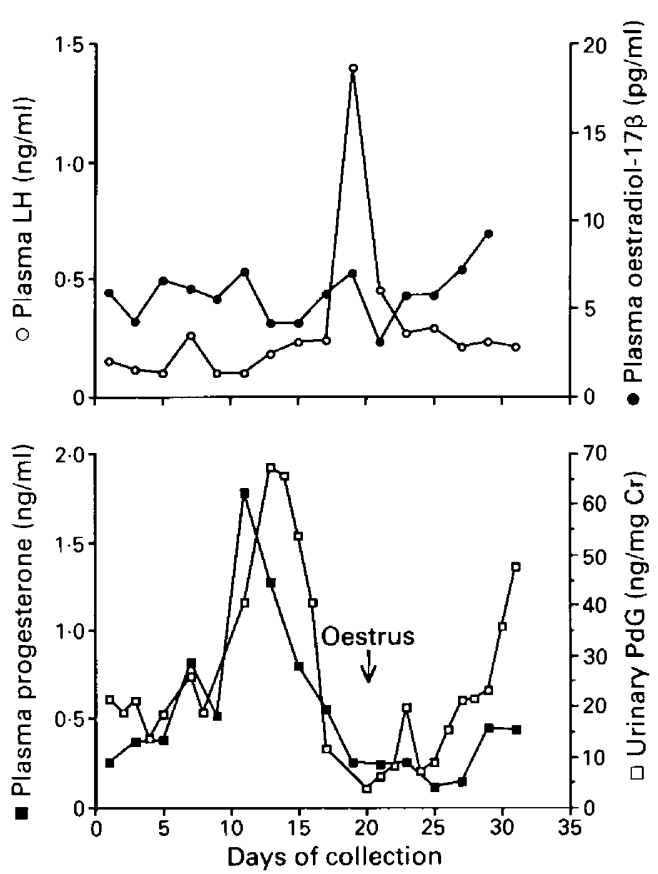

Fig. 1. Concentrations of plasma $\mathrm{LH}$, progesterone and oestradiol- $17 \beta$ and urinary PdG from a single female sampled for 1 month. Plasma samples were collected at 48 -h intervals and urine samples were collected daily. 

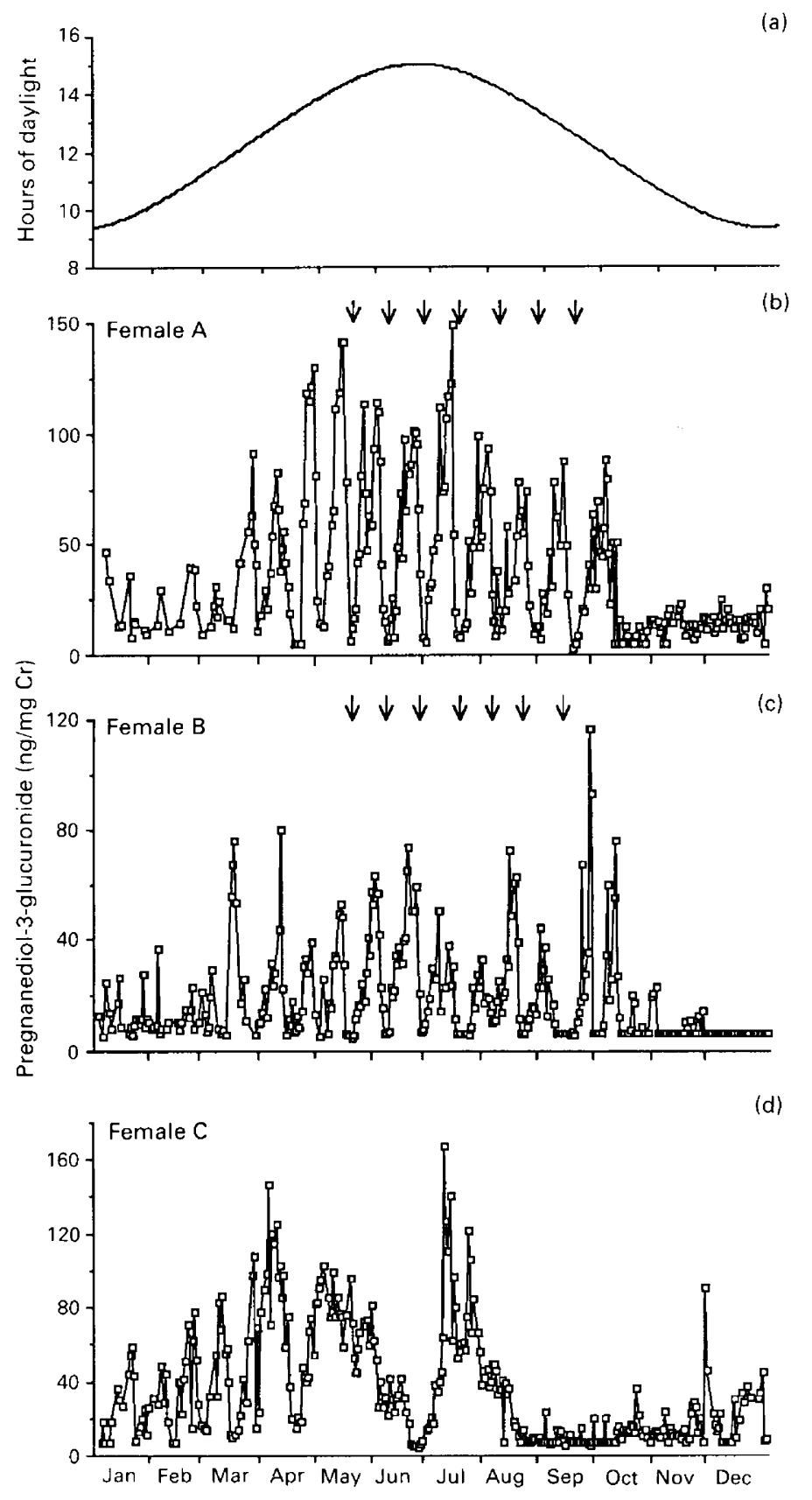

Fig. 2. Annual non-conception PdG profiles from 3 Eld's deer does sampled daily. Arrows indicate observations of behavioural oestrus and annual changes in daylength are presented in (a). Two regularly cyclic females are represented in (b) and (c); a female with consecutive prolonged luteal phases is presented in (d). 
Figure 2(a-d) depicts longitudinal PdG excretion profiles during non-conception oestrous cycles in 3 representative females monitored for 1 year. Based on variations in this metabolite, onset (January-March) and cessation (August-October) of regular cyclic hormonal activity coincided with increasing and decreasing daylengths, respectively (Fig. 2a). The overall mean of 65 oestrous cycles for the 8 females was $21 \cdot 5 \pm 2 \cdot 1$ days. However, 2 does consistently exhibited prolonged oestrous cycles (average 30.1 \pm 4.4 days; range 14-62 days, $n=14$ ) characterized by sustained elevations in PdG excretion (Fig. 2d). Excluding these cycles, the remaining females had a mean oestrous cycle duration of $18.5 \pm 0.3$ days (range 14-23 days, $n=51$ ). Behavioural oestrus (duration $\sim 12-24 \mathrm{~h}$ ) was observed in 42 of $65(64 \cdot 6 \%$ ) of the cycles, and in all cases coincided with intercyclic troughs in PdG excretion which lasted from 2 to 5 days. Only 2 does failed to exhibit signs of behavioural oestrus during the breeding season. The temporal decrease in PdG indicated that the onset of luteal regression began 3-5 days before the next observed oestrus. A maximum of 12 consecutive hormonal cycles was observed (range, 6-12) in a single individual, and no female exhibited regular metabolite fluctuations later than October.

During the breeding season, peak non-pregnant PdG concentrations ranged from $\sim 40$ to $180 \mathrm{ng} / \mathrm{mg} \mathrm{Cr}$ in non-pregnant does. At 1-6 weeks before the first behavioural oestrus and normal duration luteal phase, does always exhibited 1-3 transient increases in PdG excretion (peak, $\leqslant 50 \mathrm{ng} / \mathrm{mg} \mathrm{Cr}$ ) of several days duration (range, 2-5 days, Fig. 2b, c, d). Females also tended to exhibit an irregular excretory pattern of $\mathrm{PdG}$ following the final oestrus of the season which often was characterized by transient increases in PdG excretion similar to those observed before the first oestrus (Fig. 2c).

Although urine from all 8 non-pregnant females contained detectable quantities of oestrone conjugates (range $1 \cdot 2-57.9 \mathrm{ng} / \mathrm{mg} \mathrm{Cr}$ ), no cyclic patterns of oestrone conjugates excretion were observed. Daily urinary oestrone conjugates and PdG values in 2 non-pregnant females sampled for 3 months, beginning in March illustrated that only the latter metabolite was useful for tracking regular cyclic activity (Fig. 3 ).

Weekly mean PdG and oestrone conjugates values for the 10 pregnant does are presented in Fig. 4 with weekly values aligned to the day of parturition. Based on known copulation dates for 6 females, the mean duration of gestation was $33.5 \pm 0.4$ weeks (range 31.7-34.4 weeks). Betweenanimal variation in mean oestrone conjugates excretion over time was apparent $(P<0.003)$ while PdG levels were similar $(P>0 \cdot 10)$ among individual pregnant females. Mean PdG concentrations increased $(P<0.05)$ from $18.7 \pm 2.6 \mathrm{ng} / \mathrm{mg} \mathrm{Cr}$ (Week -34 , estimated time of conception) to $50.8 \pm 6.3 \mathrm{ng} / \mathrm{mg} \mathrm{Cr}$ by Week -32 (3rd week of gestation). PdG excretion plateaued between Week -31 and Week -25 (range 64.4-75.2 ng/mg Cr) before increasing markedly by Week -22 $(156.0 \mathrm{ng} / \mathrm{mg} \mathrm{Cr}, P<0.05)$ and then steadily rising to peak concentrations by Week -2 $(2666.0 \pm 281.5 \mathrm{ng} / \mathrm{mg} \mathrm{Cr})$. After parturition, mean PdG concentrations declined abruptly to $167.0 \pm 33.8 \mathrm{ng} / \mathrm{mg} \mathrm{Cr}$ (Week $1, P<0.05$ ) and were indistinguishable from values in non-pregnant does by Week 7 post partum $(22 \cdot 4 \pm 4.2 \mathrm{ng} / \mathrm{mg} \mathrm{Cr}, P<0.05)$.

Mean excretion of oestrone conjugates remained low during the first 5 weeks of gestation (Weeks -34 to $-30,9.6 \pm 0.5 \mathrm{ng} / \mathrm{mg} \mathrm{Cr}$ ), increased steadily to Week $-24(43.5 \pm 6 \cdot 1, P<0 \cdot 05)$ and then returned to baseline from Week $-17(10 \cdot 0 \pm 2 \cdot 1 \mathrm{ng} / \mathrm{mg} \mathrm{Cr}, P<0.05)$ to Week $-5(17.5 \pm$ $1 \cdot 3 \mathrm{ng} / \mathrm{mg} \mathrm{Cr})$. Concentrations again increased $\sim 39$-fold between Week $-4(57 \cdot 3 \pm 11 \cdot 1 \mathrm{ng} / \mathrm{mg} \mathrm{Cr})$ and Week $-1(2225.0 \pm 199.7 \mathrm{ng} / \mathrm{mg} \mathrm{Cr}, P<0.05)$ but declined precipitously immediately post partum (Week $1,160 \cdot 3 \pm 33 \cdot 7, P<0 \cdot 05$ ), and were not different from values in non-pregnant does by Week $7(24.7 \pm 6.7 \mathrm{ng} / \mathrm{mg} \mathrm{Cr}, P>0.05)$.

A representative, longitudinal excretory profile for $\mathrm{PdG}$ and oestrone conjugates is depicted in Fig. 5 ( -37 weeks before parturition through 14 weeks post partum) illustrating both the temporal and quantitative dynamics of hormonal excretion in a doe experiencing 2 non-conception reproductive cycles followed by conception and early pregnancy. After parturition, several 6-8-day transient increases in PdG were observed which were unaccompanied by behavioural oestrus. 


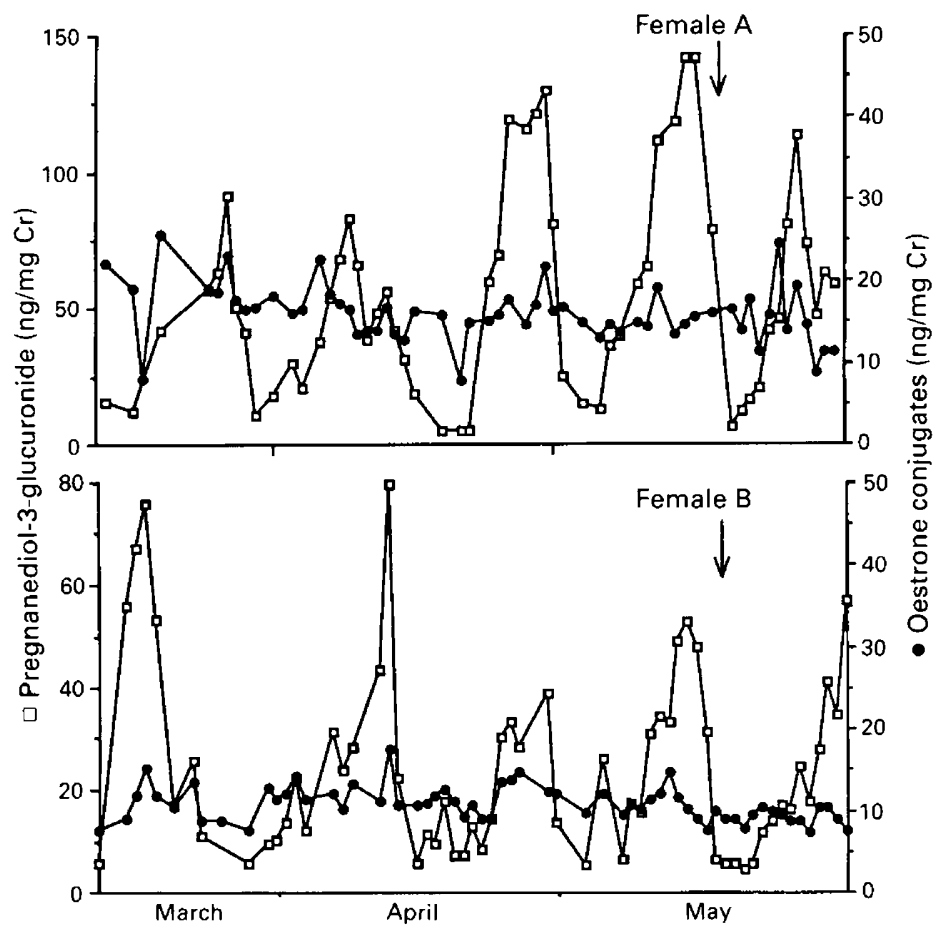

Fig. 3. Urinary concentrations of oestrone conjugates and PdG in 2 representative females sampled over a 3 month interval. Arrows denote observations of behavioural oestrus.

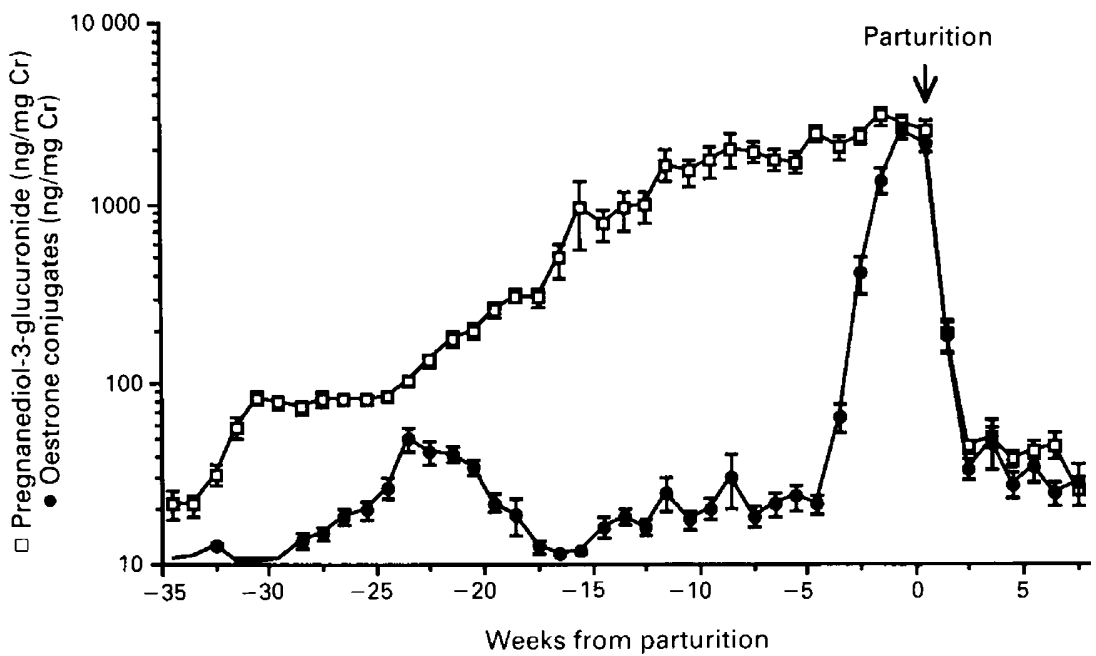

Fig. 4. Weekly (mean \pm s.e.m.) composite urinary $\mathrm{PdG}$ and oestrone conjugates profile for 10 does sampled throughout pregnancy. All values are aligned to the day of parturition.

\section{Discussion}

Longitudinal, parallel measures of urinary oestrone conjugates and PdG metabolites were useful for studying reproductive seasonality, pregnancy and parturition in the Eld's deer. These data 


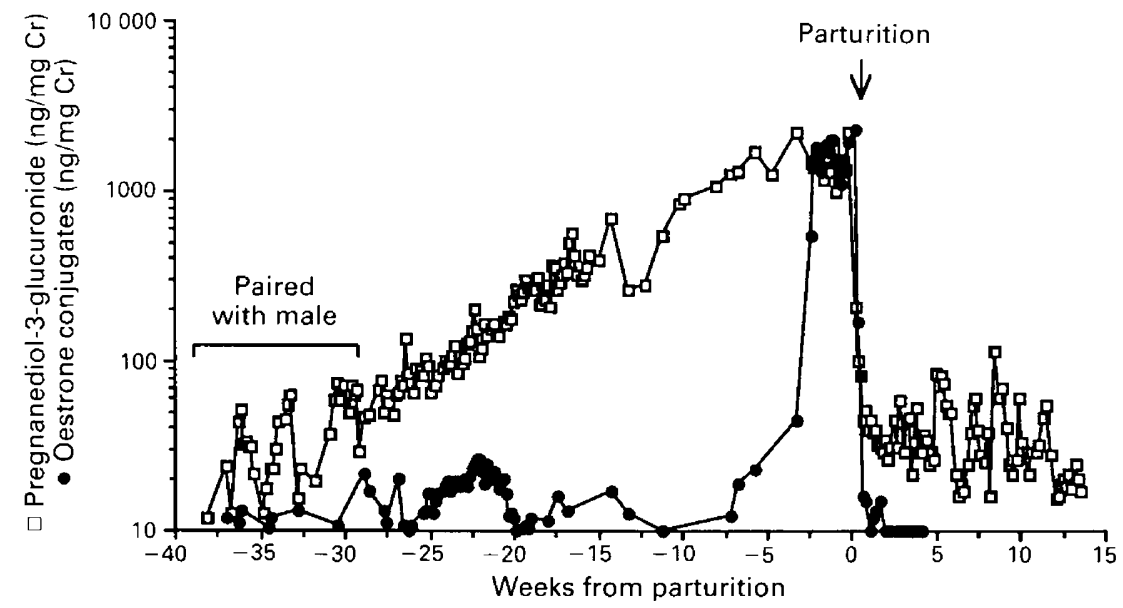

Fig. 5. Urinary oestrone conjugates and PdG concentrations in a representative female sampled from 37 weeks before parturition until 14 weeks post partum. All values are aligned to the day of parturition.

confirmed that this species is seasonally polyoestrous and a spontaneous ovulator. Oestrous cycles commence in late winter/early spring, and the potential breeding season lasts 8-9 months (JanuarySeptember). The overall mean cycle length for the Eld's deer doe was 21.5 days which was within the range reported for red deer (18.3 days: Guinness et al., 1971; 21 days: Adam et al., 1985), blacktailed deer (22-29 days: Thomas \& Cowan, 1975), white-tailed deer (28 days: Plotka et al., 1980), fallow deer (22.4 days: Asher, 1985) and Père David's deer (19.5 days: Curlewis et al., 1988). However, there was considerable variation among does which could explain the variability in cycle length reported in earlier cervid studies. The prolonged luteal-phase increases in PdG excretion (34-62 days) observed in 2 Eld's deer in our study were similar to the extended luteal phase durations reported in red deer (range 34-59 days: Guinness et al., 1971; 35 days: Adam et al., 1985) and Père David's deer (45-60 days: Curlewis et al., 1988), presumably reflecting the presence of persistent corpora lutea $(\mathrm{CL})$. For the Eld's deer, excluding these 2 does, the mean cycle length was reduced to 18.5 days which was more consistent with the observations of Wemmer \& Grodinsky (1988) who based their estimates on behavioural patterns of sexual receptivity. Oestrous behaviour coincided with troughs in PdG excretion (2-5 days duration) which was analogous to observations of baseline circulating progesterone at the time of oestrus in white-tailed deer (Plotka et al., 1980), fallow deer (Asher, 1985) and Père David's deer (Curlewis et al., 1988).

The transient, short-lived elevations in PdG occurring before the first full-length luteal phase in Eld's deer were similar to short waves of serum progesterone preceding first oestrus in red deer (Morrison, 1960), moose (Simkin, 1965), black-tailed deer (Thomas \& Cowan, 1975), white-tailed deer (Plotka et al., 1977b), reindeer and caribou (McEwen \& Whitehead, 1979), fallow deer (Asher, 1985) and Père David's deer (Curlewis et al., 1988). For the black-tailed deer, these abbreviated elevations in progesterone have been attributed to 'silent' oestrus and luteinization (but not ovulation) of ovarian follicles (Thomas \& Cowan, 1975). These transient waves of progesterone in fallow deer have been associated with the presence of CL which develop before first oestrus but fail to achieve or sustain full luteal function (Asher, 1985). The observation of transient waves of PdG excretion near the termination of the Eld's deer breeding season coincided with similar serum progesterone data in fallow deer (Asher, 1985) and may reflect a gradually reduced sensitivity of the hypothalamo-pituitary-ovarian axis as a result of the reinitiation of short-day, photoperiodic cues. It is important that these short waves of luteal function, which appear necessary for triggering later, full reproductive function, can be detected by urinary PdG excretion, thereby offering an extremely valuable tool for elucidating the mechanisms of reproductive seasonality in non-tractable species. 
In white-tailed deer, a broad 3-4-day increase in serum oestradiol-17 $\beta$ values has been reported during the follicular phase which is less distinct than the same hormone pattern reported for sheep and cattle (Plotka et al., 1977b). Although Plotka et al. (1977b) reported elevated mean oestradiol$17 \beta$ concentrations for the 3-day period immediately before oestrus in white-tailed deer, daily concentrations did not vary significantly at any stage of the oestrous cycle, reflecting the absence of a convincing preovulatory surge. Similarly, in red deer (Kelly et al., 1982) and fallow deer (Asher et al., 1986), no significant preovulatory increase in serum oestradiol-17 $\beta$ coincided with oestrus. The absence of a preovulatory increase in plasma oestradiol-17 $\beta$ in the present study may reflect the relatively infrequent blood sampling protocol or an inadequacy in assay sensitivity. Nevertheless, longitudinal excretory profiles of oestrone conjugates were not useful for monitoring ovarian function in non-pregnant Eld's deer, and this emphasizes the need to identify specific oestrogen secretion and excretion mechanisms in cervids.

Marked increases in PdG and oestrone conjugates excretion occurred during pregnancy with peak concentrations observed immediately before parturition. Increased progesterone production also has been reported for pregnant roe deer (Hoffman et al., 1978), red deer (Kelly et al., 1982), white-tailed deer (Plotka et al., 1977b), reindeer and caribou (McEwan \& Whitehead, 1979), although there are important differences in qualitative secretory profiles among species. White-tailed deer (Plotka et al., 1977b, 1982) exhibit a relatively constant secretory pattern of progesterone and require luteal-derived progesterone for pregnancy maintenance. Likewise, because the amount of progesterone secreted by pregnant red deer (Kelly et al., 1982) is directly proportional to CL number, luteal tissue probably accounts for most of the progesterone produced during pregnancy in this species. In contrast, Eld's deer exhibited PdG excretory patterns during pregnancy similar to serum progesterone profiles in roe deer, a species in which CL appear functional throughout gestation. Hoffman et al. (1978) reported that circulating progesterone in roe deer increases to a plateau during early pregnancy, is sustained for about 20 weeks and then increases again following embryonic attachment, making the roe deer the only artiodactyl known to experience obligate delayed implantation (Sempere, 1977). Whether the PdG excretory profile observed during early pregnancy in the present study reflects an abbreviated delay in implantation or a short delay in fetal-placental steroid biosynthesis is unknown. Biphasic elevations in oestrogen during pregnancy, similar to the increases in excreted oestrone conjugates observed in our study, have not been reported for other cervids. The early peak ( -29 to -19 weeks) of oestrone conjugates in the Eld's deer occurred coincident with the secondary rise in PdG following the 8-week plateau period. Perhaps these excretory profiles reflect differential secretion by the ovary and placenta.

Increased oestrogen production during late pregnancy is thought to be involved in the initiation of parturition in polyoestrous ungulates including sheep (Challis, 1971) and cattle (Edqvist et al., 1973; Smith et al., 1973; Dobson \& Dean, 1974; Robertson, 1974). The increase in urinary oestrone conjugates observed in Eld's deer ( $\sim 40$-fold) during the last 5-6 weeks of pregnancy is temporally similar to increases in serum oestrogen concentrations measured in red deer ( $\sim$-fold: Kelly et al., 1982 ) and white-tailed deer ( $\sim 7$-fold: Harder \& Woolf, 1976; $\sim 10$-fold: Plotka et al., 1977a, b). In contrast, oestrogen levels in roe deer increased steadily during the last 6 months of gestation ( 2-fold: Hoffman et al., 1978). The sharp increase in oestrone conjugates observed in all pregnant Eld's deer provided a reliable method of staging pregnancy and predicting impending parturition.

In summary, direct RIA of urinary hormonal metabolites provides a practical, stress-free approach for evaluating reproductive function in the female Eld's deer. This strategy should permit more detailed studies of the mechanisms controlling seasonality in other stress-susceptible cervid species.

We thank Jennifer Gaddish, Jan Blew, Linwood Williamson, Caroline Martinet and the many volunteers of Rivinus Barn for their diligence in obtaining samples and assisting with behavioural observations of oestrus; the curatorial and keeper staff at the Conservation and Research Center; 
Lauren Wemmer and Nicole Arthur for assistance in performing the assays; and Tim Halverson for advice on statistical analyses.

\section{References}

Adam, C.L., Moir, C.E. \& Atkinson, T. (1985) Plasma concentrations of progesterone in female red deer (Cervus elaphus) during the breeding season, pregnancy and anoestrus. J. Reprod. Fert. 75, 631-636.

Asher, G.W. (1985) Oestrous cycle and breeding season of farmed fallow deer, Dama dama. J. Reprod. Fert. $75,521-529$.

Asher, G.W., Barrell, G.K. \& Peterson, A.J. (1986) Hormonal changes around oestrus of farmed fallow deer, Dama dama. J. Reprod. Fert. 78, 487-496.

Asher, G.W., Peterson, A.J. \& Duganzich, D. (1989) Adrenal and ovarian sources of progesterone secretion in young female fallow deer, Dama dama. J. Reprod. Fert. 85, 667-675.

Challis, J.R.G. (1971) Sharp increase in free circulating oestrogens immediately before parturition in sheep. Nature, Lond. 229, 308.

Curlewis, J.D., Loudon, A.S.I. \& Coleman, A.P.M. (1988) Oestrous cycles and the breeding season of the Père David's deer hind (Elaphurus davidianus). $J$. Reprod. Fert. 82, 119-126.

Dobson, H. \& Dean, P.D.G. (1974) Radioimmunoassay of oestrone, oestradiol-17 $\alpha$ and $-17 \beta$ in bovine plasma during the oestrous cycle and last stages of pregnancy. J. Endocr. 61, 479-486.

Edqvist, L.E., Ekman, L., Gustafsson, B. \& Johansson, E.D.B. (1973) Peripheral plasma levels of oestrogens and progesterone during late bovine pregnancy. Acta endocr., Copenh. 72, 81-88.

Evans, K.L., Hughes, J.P., Couto, M., Kasman, L.H. \& Lasley, B.L. (1984) Pregnancy diagnosis in the domestic horse through direct urinary estrone conjugate analysis. Theriogenology 22, 615-620.

Fisher, R.A. (1966) The Design of Experiments, 8th edn. Oliver and Boyd, Edinburgh.

Guinness, F., Lincoln, G.A. \& Short, R.V. (1971) The reproductive cycle of the female red deer, Cervus elaphus L. J. Reprod. Fert. 27, 427-438.

Harder, J.D. \& Woolf, A. (1976) Changes in plasma levels of oestrone and oestradiol during pregnancy and parturition in white-tailed deer. J. Reprod. Fert. 47, $161-163$.

Hoffman, B., Barth, D. \& Karg, H. (1978) Progesterone and estrogen levels in peripheral plasma of the pregnant and nonpregnant roe deer (Capreolus capreolus). Biol. Reprod. 19, 931-935.

Kasman, L.H., McCowan, C. \& Lasley, B.L. (1985) Pregnancy detection in tapirs by direct urinary estrone sulfate analysis. Zoo Biol. 4, 301-306.

Kasman, L.H., Ramsay, E.C. \& Lasley, B.L. (1986) Urinary steroid evaluations to monitor ovarian function in exotic ungulates: III. Estrone sulfate and pregnanediol-3-glucuronide excretion in the Indian rhinoceros (Rhinoceros unicornis). Zoo Biol. 5, 355-361.

Kelly, R.W., McNatty, K.P., Moore, G.H., Ross, D. \& Gibb, M. (1982) Plasma concentrations of LH, prolactin, oestradiol, and progesterone in female red deer (Cervus elaphus) during pregnancy. J. Reprod. Fert. 64, 475-483.

Kirkpatrick, J.F., Kasman, L.H., Lasley, B.L. \& Turner, J.W. (1988) Pregnancy determination in uncaptured feral horses. J. Wildl. Mgt 52, 305-308.

Loskutoff, N.M., Ott, J.E. \& Lasley, B.L. (1982) Urinary steroid evaluations to monitor ovarian function in exotic ungulates: I. Pregnanediol-3-glucuronide immunoreactivity in the okapi. Zoo Biol. 1, 45-53.

Loskutoff, N.M., Ott, J.E. \& Lasley, B.L. (1983) Strategies for assessing ovarian function in exotic species. J. Zoo Anim. Med. 14, 3-10.

Loskutoff, N.M., Walker, L., Ott-Joslin, J.E., Raphael, B.L. \& Lasley, B.L. (1986) Urinary steroid evaluations to monitor ovarian function in exotic ungulates: II. Comparison between the giraffe (Giraffa camelopardalis) and the okapi (Okapia johnstoni). Zoo Biol. 5, 331-338.

McEwan, E.H. \& Whitehead, P.E. (1979) Plasma progesterone levels during anestrus, estrus, and pregnancy in reindeer and caribou (Rangifer tarandus). Proc. 2nd Int. Reindeer/Caribou Symp. Roros, Norway, 34-38.

Mitchell, W.R., Presley, S., Czekala, N.M. \& Lasley, B.L. (1982) Urinary immunoreactive estrogen and pregnanediol-3-glucuronide during the normal menstrual cycle of the female lowland gorilla (Gorilla gorilla). Am. J. Primatol. 2, 167-175.

Morrison, J.A. (1960) Ovarian characteristics in elk of known breeding history. J. Wildl. Mgt 24, 297-307.

Niswender, G.D., Reichert, L.E., Midgley, A.R. \& Nalbandov, A.V. (1969) Radioimmunoassay for bovine and ovine luteinizing hormones. Endocrinology' 84, 1166-1173.

Plotka, E.D., Seal, U.S., Schmoller, G.C., Karns, P.D. \& Keenlyne, K.D. (1977a) Reproductive steroids in the white-tailed deer (Odocoileus virginianus borealis). I. Seasonal changes in the female. Biol. Reprod. 16, 340-343.

Plotka, E.D., Seal, U.S., Verme, L.J. \& Ozoga, J.J. (1977b) Reproductive steroids in white-tailed deer (Odocoileus virginianus borealis). II. Progesterone and estrogen levels in peripheral plasma during pregnancy. Biol. Reprod. 17, 78-83.

Plotka, E.D., Seal, U.S., Verme, L.J. \& Ozoga, J.J. (1980) Reproductive steroids in deer. III. Luteinizing hormone, estradiol, and progesterone around estrus. Biol. Reprod. 22, 576-581.

Plotka, E.D., Seal, U.S., Verme, L.J. \& Ozoga, J.J. (1982) Reproductive steroids in white-tailed deer. IV. Origin of progesterone during pregnancy. Biol. Reprod. 26, 258-262.

Plotka, E.D., Seal, U.S., Verme, L.J. \& Ozoga, J.J. (1983) The adrenal gland in white-tailed deer: A significant source of progesterone. J. Wildl. Mgt 47, 38-44.

Ramsay, E.C., Kasman, L.H. \& Lasley, B.L. (1987) Urinary steroid evaluations to monitor ovarian function in exotic ungulates: V. Estrogen and pregnanediol- 
3-glucuronide in the black rhinoceros (Diceros bicornis). Zoo Biol. 6, 275-282.

Robertson, H.A. (1974) Changes in concentration of unconjugated oestrone, oestradiol-1 $7 \alpha$, and oestradiol$17 \beta$ in the maternal plasma of the pregnant cow in the relation to the initiation of parturition and lactation. J. Reprod. Fert. 36, 1-7.

Schams, D., Barth, D. \& Karg, H. (1980) LH, FSH, and progesterone concentrations in peripheral plasma of the female roe deer (Capreolus capreolus) during the rutting season. J. Reprod. Fert. 60, 109-114.

Sempere, A. (1977) Plasma progesterone levels in the roe deer, Capreolus capreolus. J. Reprod. Fert. 50, 365-366.

Shideler, S.E., Czekala, N.M., Kasman, L.H., Lindburg, D.G. \& Lasley, B.L. (1983) Monitoring ovulation and implantation in the lion-tailed macaque (Macaca silenus) through urinary estrone conjugate evaluations. Biol. Reprod. 29, 905-911.
Simkin, S.W. (1965) Reproduction and productivity of moose in Northwestern Ontario. J. Wildl. Mgt 29, 740-750.

Smith, V.G., Edgerton, L.A., Hafs, H.D. \& Convey, E.M. (1973) Bovine serum estrogens, progestins, and glucocorticoids during late pregnancy, parturition, and early lactation. J. Anim. Sci. 36, 391-396.

Taussky, H.H. (1954) A microcolorimetric determination of creatinine in urine by the Jaffe reaction. $J$. biol. Chem. 208, 853-861.

Thomas, D.C. \& Cowan, McT.I. (1975) The pattern of reproduction in female Columbian black-tailed deer, Odocoileus hemionus columbianus. J. Reprod. Fert. 44, 261-272.

Wemmer, C. \& Grodinsky, G. (1988) Reproduction in captive female brow-antlered deer (Cervus eldi thiamin). J. Mammal. 69, 389-393.

Received 8 May 1989 